\title{
Challenges Facing Uptake of Hand Washing With Soap Programme in Schools in Tana Delta Sub County.
}

\author{
Davies Kodi. Mwachiro \\ ST/NO. HD317-COO5-3310/2012
}

\begin{abstract}
The focus of this research project was to determine the challenges facing uptake of hand washing with soap programme in schools in Tana Delta Sub County. Premised on ,this research was guided by objectives including to determine school children's perception of dirt, to establish school children risky hygiene practices, to determine school children motivational factors to hand washing with soap and to establish school children knowledge on the importance of hand washing with soap. The research project was conducted in Tana Delta Sub County. It applied descriptive design of research. The target population was 550 respondents but $10 \%$ of the population was a representative of the study population which was 55 respondent. Data was collected using questionnaires and collected data was organized in terms of variables and each response counted. This research project formulated some recommendations which when implemented will upscale uptake of hand washing with soap programme in schools.

Despite the importance of hand washing with soap in the prevention of diarrheal diseases among school going children, the problem we have is that hand washing with soap programmes are not being prioritized in schools. When it comes down to changing good hygiene practices, children, the segment of society so often the most energetic, enthusiastic and open to new ideas - can act as agents of change by taking the hand washing lessons 'learned at school back into their homes and communities. Data was collected using questionnaires with a set of questions administered by the interviewer to the respondents. The questionnaires were administered to the teachers by the enumerators and after filling of the responses, all the questionnaires were submitted to the researcher for analysis and compilation. Data was analyzed through the use of SPSS version 20, where both descriptive and inferential statistics such as means, standard deviations and correlations were done. The findings are presented in tables and figures and interpretations made in a continuous prose in explanations. Study findings revealed that challenges affecting uptake of hand washing with soap programme in schools include lack of soap provision in schools, water in adequacy, disappearance of soap and hand washing facilities. Major recommendations include provision and use of soap for hand washing for hand washing in schools, provision of enough water in schools as this program cannot pick if there is water shortage.
\end{abstract}

\subsection{Background}

\section{Introduction}

Hand washing with soap and water is among the most effective and inexpensive way to prevent diarrheal diseases and pneumonia which together are responsible for the majority of child deaths. This behavior is projected to become a significant contribution to meeting the Millennium Development friction Goal of reducing death among children under the age of five by two thirds by 2015 . October 15 has been appointed to become Global Hand washing Day in accordance with year 2008 as the International Year of Sanitation by the United Nations. Hands always act as the vectors that carry disease causing pathogens from person to person, either through direct contact or indirect via surfaces (WHO Reg Health Forum 2003).

Human can spread bacteria though touching other peoples' hands, hair, nose and face. Hands that have been in contact with human or animal feces, bodily fluids like nasal excretions and contaminated foods or water can transport bacteria, viruses and parasites to unwitting hosts. Hand washing with soap works by interrupting the transmission of the disease. Washing hands with water alone is significantly less effective than washing hand with soap in terms of removing germs. Although using soap in hand washing breaks down grease and dirt that carry most germs, using soap also means additional time consumed during massaging, rubbing and to dislodge them from fingertips and between the fingers, in comparison to just using water for hand washing. Effective hand washing with soap takes 8-15 seconds, followed by though rinsing of hands with running water. Aiello\& Levy (2007).

Globally, in Vietnam and Peru, hand washing initiatives within the primary school setting, is increasing students' hand washing with soap rates by using entertainment education approaches. The initiatives were supported by the Water and Sanitation Program (WSP) through the Global Scaling up Hand washing Project. In Vietnam, the Women's Union facilitated the training of 1,200 headmasters and teachers who carried out hand washing activities in over 600 schools in 15 provinces across the country. In total, over 340,000 students were 
reached. In Peru, the Hand washing Initiative was mainstreamed into the Ministry of Education's system, through the Safe, Clean and Healthy Schools Program that was implemented in 24 regions and trained 14,000 teachers who worked with 285,000 students. (WHO Reg Health Forum 2003).

Although both countries based their program development on a common framework under the Global Hand washing scaling up Project, their implementation strategies were markedly different. The need for formative research insights that would help drive the design of the programs was a key lesson from those programs. One relevant finding common to both countries was the fact that children already understood the value of washing hands to combat germs. That was a platform used in building the programs. Research in Vietnam revealed that children had very little free time and that teachers were already overburdened with a heavy curriculum. Therefore, the entertainment education approach was used to develop games and activities as extracurricular activities that would complement rather than compete with the existing curriculum. In Peru, the curriculum became the entry point for the program, particularly because the Education Ministry was ready to improve the national hygiene curriculum though policy development and regulations. Yaicin \& Aitin (2004).

In both countries, the formative research sought to understand whether the children could act as agents of change in their households and schools. In Vietnam, the ideal child was docile and submissive and unlikely to be able to influence adults. Children could, however, influence their siblings. Therefore, in Vietnam the program focus was on hand washing with soap to prevent others from getting sick. In Peru, children in most areas were motivated to "help" their families to overcome certain burdens to come out of poverty. Children are therefore, motivated to influence their elders, to the program focused on their ability to become agents of change and some messages asked of them to remind their mothers to wash their hands with soap before cooking. Both programs utilized fun and games with a superhero character that used soap to help others. However, the messaging and mechanisms for relaying messages differed according to the results of the research .UNICEF, state of the world's children.(2008).

The fact that teachers needed incentives was also a key lesson. In Peru, teachers were overburdened with activities and capacity-building sessions. Teachers needed to perceive a concrete benefit from additional commitments. Linking the HWI program to performance indicators and recognizing progress by means of certifications, proved to be effective because it translated in increases in teachers' salary rates. In Vietnam, equipping teachers with a different approach to hygiene promotion and giving them simple tools that they could immediately integrate into their lessons proved to be an invaluable incentive. In both countries, a key aspect of the programs was the capacity to be a bridge between the school and the home and to link children to the larger community. In Vietnam's caretakers program, grandparents received messages on the importance of washing their own hands at key times. They also received guidance on how to play games with their grandchildren to help reinforce hand washing with soap messages delivered in schools .Yaicin \&Aitin (2004).

In both countries, mass media helped to link children to the larger community. In the case of Vietnam, it reinforced the school-based hand washing activities through national television programs, publications, and drawing contests. In Peru's case, radio campaigns were supported by interpersonal programs carried out in schools and elsewhere in each district where the project was implemented. Both case studies also offered suggestions on how to integrate hand washing with soap to increase its occurrence rate, by partnering with other actors in the water, sanitation and health sector or by mainstreaming hand washing with soap into education systems through policy, regulation and rewards. Regardless of the approach taken, both country case studies demonstrated that getting more children to wash their hands with soap was achievable. Aiello \& Levy (2007).

Project impact evaluation analyses in both countries are currently underway and the lessons provided in the present document are based on monitoring analysis of the behavioral change process in primary schools over the 2008 to 2010period. Growing demand by national and local authorities to continue, scale up and further integrate approaches and tools developed by the project will lead to additional learning. These lessons should provide useful insights for governments, practitioners (including teachers and educators), NGOs and donors, who are interested in implementing a hand washing program in primary schools.

In Kenya, following the implementation of Free Primary Education (FPE) in 2003, sanitation and school infrastructures have been severely constrained. According to the Economic Survey, 2006, school enrollment increased from 5.4 million children in 2001 to 7.6 million in 2005. The expansion of facilities has been slow compared to this growth in enrollment. Existing school infrastructure has also been suffering from a lack of investments over a number of years. Most schools have overcrowded classrooms and inadequate water and sanitation facilities.

The requirement for additional investment in primary school infrastructure is particularly acute in urban slums and the poorest areas in Kenya. The school toilet standards are way below the recommended international standards. A rapid assessment in public schools in Nairobi, Machakos, Kajiado, and Kiambu districts in 2004 revealed a toilet ratio of: 64. The toilet ratio in Mombasa Municipality public schools is way below the international standard of 5 for girls and 5 for boys (with urinal). According to discussions with members of the School. Infrastructure Management Unit (SIMU), there is a lack of comprehensive data 
on the number of schools in Kenya with running water and hand washing facilities. However, an audit of the, 04 schools revealed that only a negligible proportion had hand washing facilities (possibly as low as 5 percent). The rapid assessment mentioned above revealed that over 90 percent of schools in rural Kenya lack a source of safe water and do not have any hand washing facility. According to the Mombasa Municipality, less than 50 percent in Mombasa are connected with piped water system while 0 percent must use water from contaminated wells despite the fact that the UNICEF Kenya office has been working with the city council to improve sanitation in schools. WELL fact sheet, (2004)

Other than the fact that toilet facilities are inadequate and overstretched, most are dirty. An observation of schools where this study was carried out revealed the pathetic conditions of the toilets. The toilet floors were soiled with feces and wet with urine. Most girls' toilets and urinals had a strong stench. Some had urine collecting in the corners, other had feces on the walls. This poses a serious health risk for children considering that some children in rural areas go to school bare-footed. The government has come up with School Infrastructure Improvement Grant (SIIG) in which, 04schools were identified as beneficiaries. The selection of schools was based on current poverty constituency indices compiled by the Central Bureau of Statistics (CBS) and physical infrastructure conditions and enrollment statistics from the Ministry of Education (MoE). Hand washing facilities have been incorporated in the infrastructure.

Some schools, as in Kirinyaga district, have water but poor sanitation. They have received funding from JICA to improve the facilities. WHO and UNICEF are currently in the process of providing water facilities to selected schools. CARE is also working in Nyanza to improve access to water in schools. According to the MoE, hand washing falls within the scope of Sanitation and hygiene. It needs to be packaged as such for acceptability, especially amongst $\mathrm{MoE}$ stakeholders. Therefore, hand washing campaigns in schools need to be integrated with other existing programs, such as deworming. UNICEF, State of the world's children. (2008)

In Kenya, the program was piloted in about 200 schools in two western provinces. Trained teams went out to primary schools and promoted the SOPO program with the help of the cartoon ambassador, a friendly green bar of soap. The teams taught kids a catchy song that reminded them when they should wash their hands. The teams urged the schools to maintain hand-washing facilities and promote an environment at school where students reminded and encouraged each other to wash.

Before deciding on scaling up the program to a national level, UNICEF and the Kenyan government wanted to understand the impact of the program in the pilot areas. Did children remember SOPO and did their hand-washing improve in response to the program? Was the SOPO program an efficient use of limited funds available to support hygiene in schools?

School children in many areas of the world do not have easy access to soap and water. In elementary school, there were shorter sinks for younger grades so that even the smallest children could reach the taps. And soap was always available; soap dispensers were located at each sink and refilled daily. In this technological age, we may be inclined to look for high-tech solutions to health problems, but the greatest impact may come from a low-tech solution, such as figuring out a way to keep soap and water available to schoolchildren in lowresource settings so they can wash their hands.. WELL fact sheet,(2004)

In Tana Delta Sub County, hand washing with soap programme in schools is still very low and there is a lot that is required to be done to ensure that this programme is implemented and sustained. The table below shows the status of hand washing programmes in schools.

Table 1.1A table showing distribution of schools with hand washing facilities.

\begin{tabular}{lll}
\hline Division & No. schools & No. of schools with hand washing facilities. \\
\hline Tarasaa & 17 & 3 \\
\hline Garsen & 28 & 2 \\
\hline Kipini & 9 & 2 \\
\hline
\end{tabular}

Source: District Public Health office- Tana Delta Sub County, (2014)

My target group in my research will be school teachers in all public primary schools in Tana Delta Sub County and the target population is about 550 teachers. The numbers of public primary schools are 55 and an average number of teachers per school is about 10 and this gives my target population to be to be 550 teachers.

\subsection{Problem Statement}

The whole intent of a progromme is to meet a predetermined objective. That said then the intent of hand washing with soap programme is to ensure that it is promoted and sustained so as to prevent diarrheal diseases. In Kenya, following the implementation of Free Primary Education (FPE) in 2003, sanitation and school infrastructures have been severely constrained. According to the Economic Survey, 2006, school enrollment increased from 5.4 million children in 2001 to 7.6 million in 2005. The expansion of facilities has been slow compared to this growth in enrollment. Existing school infrastructure has also been suffering 
from a lack of investments over a number of years. Most schools have overcrowded classrooms and inadequate water and sanitation facilities.

Hands washing with soap programmes are not being prioritized in schools despite their importance in the prevention of diarrheal diseases among school going children and the community at large. Hand washing with soap programme should even be included in the school curriculum so that emphasis and practice on the same can be done at schools. When it comes down to changing good hygiene practices, children, the segment of society so often the most energetic, enthusiastic and open to new ideas - can act as agents of change by taking the hand washing lessons 'learned at school back into their homes and communities. The active participation and involvement of children - ideally situated at the intersection of the home, school and community-based intervention can really improve the situation

In Tana Delta Sub County, only a negligible number of public primary schools have hand initiated hand washing programmes though at a small scale. Due to the importance of hand washing with soap, "WHO" came up with a "GLOBAL HANDWASHING DAY" which was first launched on 15th October 2009 and since that time all countries commemorate 15th October every year as a Global hand washing day World Wide, Countries are celebrating Global Hand washing Day where several activities take place Including hand washing with soap campaign in school, and villages. Demonstration on hand washing activities in the same places. The challenge is to transform hand washing with soap from abstract good ideas into an automatic behavior performed in homes, schools and communities worldwide. More hand washing with soap would make a significant contribution to meeting the Millennium Development Goal of reducing deaths among children under the age of five by two thirds by 2015.Fewtrelletal,(2005).

Network for Water and Sanitation (NETWAS), UNICEF, and African Medical and Research Foundation (AMREF) in partnership with other stakeholders such as the Ministry of Health have established initiatives in schools. These initiatives are, however, not specific to hand washing but to hygiene in general, and have been implemented through the formation of WASH and Hygiene clubs in schools. The organizations also coordinate seminars for leaders of these clubs and teachers. Their initiatives include (a) using leaky tins in areas with a shortage of hand washing facilities; and (b) asking children to carry water in the morning to cater for water shortage in schools. However, hand washing with soap (HWWS) has not been emphasized, except in Olympic Primary School which did try the initiative but discontinued it in the face of challenges.

A review of the initiatives provides lesson such as initiative to consider soap in liquid form rather than as a bar or powder, need for improvised soap dispensers to reduce wastage of soap, need to involve the Ministry of Education to recognize HWWS in schools as an important step towards safeguarding the health of the children Currently, the Ministry has undertaken other initiatives, such as deworming, which has an association with hand washing. HWWS cannot work in isolation; it requires to be integrated into the whole concept of hygiene. Teachers and school administrations need to buy into the idea in order to continuously promote the initiative and also teachers supporting the initiative should receive recognition, not necessarily monetary. Currently the effectiveness of the clubs is decreasing due to a lack of support by teachers who perceive it as an addition to their workload .UNICEF, state of the word's children. (2008)

There is a gap in hand washing with soap programme in schools in spite of its importance and it seems challenges facing implementation and sustaining the programme have not been addressed. My study is looking at challenges facing this programme and also gives some recommendation on the same.

\subsection{Research Objectives \\ 1.3.1General objective}

To analyze challenges facing uptake of hand washing with soap programme in schools in Tana Delta Sub County.

\subsubsection{Specific objectives}

1. To determine school children's perception of dirt and their influence on hand washing with soap.

2. To establish the risky hygienic practices of school children and their influence on hand washing with soap.

3. To determine school children's motivational factors and their influence to hand washing with soap.

4. To establish if the school children know the importance of hand washing with soap.

\subsection{Research Question}

1. How does perception of dirt influence hand washing with soap?

2. What is the influence of school children's risky hygienic practices on hand washing with soap?

3. What is the influence of schoolchildren's motivational factors to hand washing with soap?

4. What is the influence of school children's awareness on hand washing with soap? 


\subsection{Justification}

Hand washing with soap particularly at critical moments includes after using the toilet and before handling food is a key cost effective and life saving intervention. Research in several developing countries illustrates that lack of soap is usually not the barrier with the vast majority of even the poor households having soap at home rather the problem is that soap is rarely used for hand washing. This research is aimed at coming up with new knowledge concerning factors which will promote hand washing with soap. It will also assist in planning and delivering of health services to target groups .Murray \& Lopez, (1997)

Hand washing with soap (HWWS) is among the most effective and inexpensive ways to prevent diarrheal diseases and pneumonia, which together are responsible for the majority of child deaths. This behavior is projected to become a significant contribution to meeting the Millennium Development Goal of reducing deaths among children under the age of five by two-thirds by 2015 . October 15 has been appointed to become Global Hand washing Day in accordance with year 2008 as the International Year of Sanitation by the United Nations.

Hands often act as vectors that carry disease-causing pathogens from person to person, either through direct contact or indirectly via surfaces. Humans can spread bacteria by touching other people's hand, hair, nose, and face. Hands that have been in contact with human or animal feces, bodily fluids like nasal excretions, and contaminated foods or water can transport bacteria, viruses and parasites to unwitting hosts. Hand washing with soap works by interrupting the transmission of disease. Washing hands with water alone is significantly less effective than washing hands with soap in terms of removing germs. Although using soap in hand washing breaks down the grease and dirt that carry most germs, using soap also means additional time consumed during the massaging, rubbing, and friction to dislodge them from fingertips, and between the fingers, in comparison with just using water for hand washing. Effective hand-washing with soap takes $8-15$ seconds, followed by thorough rinsing with running water.

\subsubsection{Significance of the study}

The significance of the study is that it will be beneficial to the community of Tana Delta Sub County at large; this is because messages about hand washing with soap will reach to parents, guardians, caretakers through school children who will have been sensitized by teachers at school on the same. This will also be coupled by installation of hand washing with soap stations at various points including just outside all sanitary facilities so that children wash their hands immediately after visiting the toilet and near the school kitchen so that children wash their hands before served with lunch.

School going children will also be the beneficiary for this study because they spend most of their time in school and trust their teachers more because they are their parents during schools hours. The behavior they will acquire from school will create a future positive impact hence behavior of hand washing with soap in schools will be inbuilt in school going children thus having healthy school children.

The Ministry of Health should provide support for regular follow up in schools by the Ministry staff to ensure that hand washing with soap is practiced in and also availability of hand washing facilities with water and soap. Both Ministries of Health and Education should integrate hand washing with soap programmes in their strategic plans for schools in Tana Delta Sub County.

To adequately address this issue of challenges facing hand washing with soap programme in schools, the fact of involving the stakeholders need not be overlooked as they play a vital role. The effects of their involvement need to be studied and established. Finally information is key for any programme implementation, since the effects of public awareness campaign among citizens need to be established in relation to challenges facing hand washing with soap programme in schools in Tana Delta Sub County and how it contributes to disease control.

This study will improve literature on challenges facing hand washing with soap programme in schools in Tana Delta Sub County. This study will also enable me meet the partial requirement for the award of Master of Science degree in Project Management of Jomo Kenyatta University of Agriculture and Technology, Mombasa CBD Campus. With integration of all these plans and Strategy, the sub county will be able to improve on hand washing with soap programme in schools.

\subsection{Scope.}

The study will cover 55 public primary schools in Tana Delta Sub County of Tana River County. The respondents will be teachers in charge of health clubs in the schools. It will be limited to challenges facing hand washing with soap programme in schools.

\subsection{Study Limitation.}

The study limitation encountered was insecurity of the area which hindered visit to the areas not visited and this is because of the tension and fear of banditry in those particular areas. 


\subsection{Introduction}

\section{Literature Review}

This chapter contextualizes the present study within the literature review delving into the challenges facing hand washing with soap programme in schools as presented by various scholars, analysts and authors. Hand washing with soap particularly at critical moments including after using the toilet and before handling food is a key cost effective and life saving intervention. Research in several developing countries illustrates that lack of soap is usually not the barrier with the vast majority of even poor households having soap at home rather the problem is that soap is rarely used for hand washing.

\subsection{Hand Washing Theories}

Some hand washing theories include the following;

\subsubsection{Semmelweis Germ Theory}

Dr. Ignaz Semmelweis discovered the theory in 1860 (when he was 42 years old) while in Hungary. He is known for introducing disinfection standards, in obstetrical clinics, from 1847.Ignaz Philipp Semmelweis was a Hungarian physician of German extraction now known as an early pioneer of antiseptic procedures, described as the "savior of mothers," Semmelweis discovered that the incidence of puerperal fever could be drastically reduce by the use of hand disinfection in obstetrical clinics. Puerperal Fever was common in mid $19^{\text {th }}$ century hospitals and often fatal, with mortality at $10 \%-35 \%$, Semmelweis proposed the practice of hand washing with chlorinated lime solutions in 1847 while working in Vienna General Hospital. First obstetrical clinic where doctor's wards had three times the mortality of midwives wards. He published a book of his findings in Etiology, concept and prophylaxis of childbed fever.

Despite various publications of results where hand washing reduced mortality to below $1 \%$, Semmelweis observation conflicted with the established scientific and medical opinions of the time and his idea were rejected by the medical. Some doctors were offended at the suggestion that they should wash their hands and Semmelweis could offer no acceptable scientific explanation for his findings. Semmelweis practice earned widespread acceptance only years after his death when Louis Pasteur confirmed the germ theory and Joseph Lister, acting on the French microbiologist's research, practiced and operated, using hygienic methods, with great success.

\subsubsection{Hand washing Theory}

Hand washing theory is the teaching, as opposed the practice, of the first line of defense against cross contamination of pathogenic microorganisms. The U.S. Center for Disease control maintains that hand washing is one of the most effective means of preventing the spread of disease. Beginning in the 1800s, medical professionals began to implement hand washing rules, which largely reduced in stay hospital fatality counts. In modern times, hand washing is still a critical element of proper hygiene. Cross contamination is still largely to blame for food borne viral infections and cases of hospital disease transference, Bolt \& Krukkert (2006).

\subsubsection{Behavioral theory}

This behavior assumes that a success of a person is based solely on the behavior of a person. Behavioral theory is used a lot in teaching. It is also assumed that people are not born leaders but they can be trained to become effective leaders. Hand washing with soap programme is based on teaching the behavior of accepting the practice of hand washing with soap at four critical moments to prevent disease causing germs from getting into our bodies.

\subsection{Conceptual frame work.}

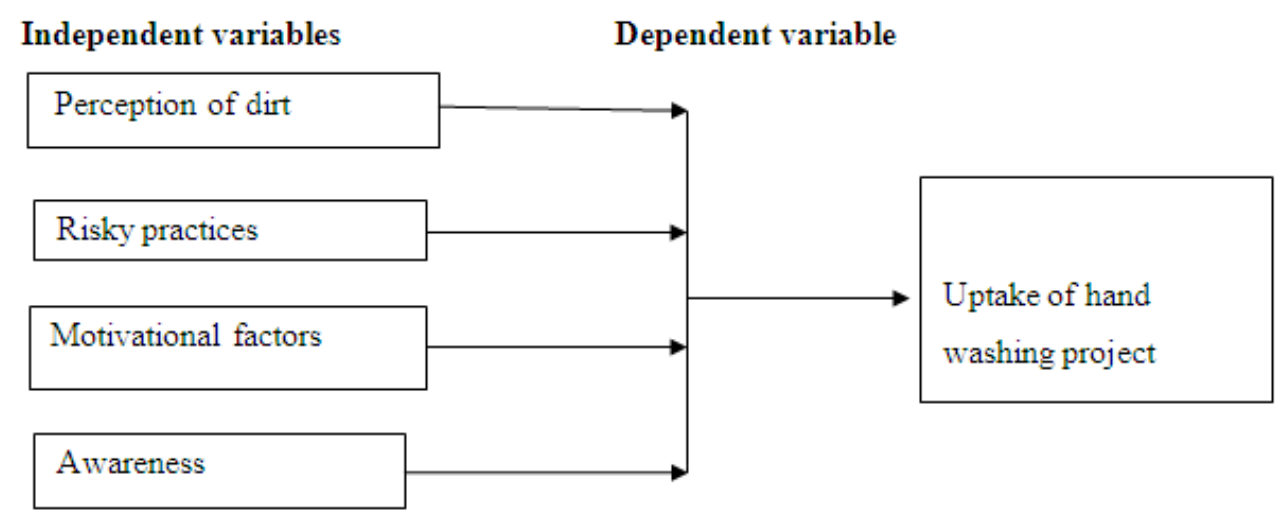




\subsubsection{Perception of dirt.}

From the children's perspective, dirt is "physical contact with germs or bacteria which are invisible to the naked eye". Surfaces where germs are likely to be present are: dirty surfaces, for example, toilet walls, floors (dust or mud); dirty objects, such as brooms, mops, cash notes, writing stationery, or contact with feces; working environment, for example, on farms; poor personal hygiene standards, for instance, long nails, dirty hands; and dirty water or food. Given the definition of dirt, situations where one is likely to wash hands with soap are numerous. Soap is associated with germ removal as it contains "some chemicals with ability to remove germs". Medicated soaps are top on the list. Other means for germ removal include use of insecticides "to kill insects that carry germs", and boiling or treating water. They say that you should get rid of germs after using the toilet, and avoid taking in germs before eating. Despite the high association between soap and the removal of "germs from the toilet", soap is used more for hygiene maintenance (personal and physical environment), but not for hand washing. Warm water or scrubs (such as sand and stone) are perceived to be a substitute for soap by a few people.

Children do not perceive dirt as something that can make them sick due to lack of knowledge on dangers associated with dirt. This is evidenced by their playing environment and kits where hands are actively involved. If they had information about dirt then they could have stopped playing in filthy environments. UNICEF, state of the word's children. (2008).

\subsubsection{Risky practices}

Unhygienic risky hand practices include use of bear hands for anal cleansing and this is evidenced by finger marks on the inner latrine walls where hands are wiped for cleaning. After this, children continue with other day to day activities including eating and even sharing of food to other children using the same hands. Changing of sanitary towels among girls is also another risky unhygienic hand use taking into consideration that the sanitary towels are soaked with menstrual blood and the same hands will also be used for eating. Sacking of fingers is also a common risky unhygienic hand practice taking into consideration of the activities performed by use of hands. This means all the dirt attached to the hands will be swallowed in the stomach. Washing of the baby bottom after the baby has answered a call of nature using bear hands. This child may not be having any information about hand washing with soap after this exercise. This happens especially if children have been left by their parents to take care of young ones. This Child can get infected in the process or even re-infect the same child while in the process of feeding the same child. UNICEF, state of the word's children. (2008).

\subsubsection{Motivational factors}

According to Rabie, \&Curtis (2006), motivational factors for hand washing include disgust as strongest motivator where there is strong smell and physical dirt. It is a strong motivator after using the toilet and when in contact with stool. Nurturing act as a strong emotional motivator to protect children from illness and see them grow to achieve the dreams parents have for them. Nurture is an effective motivator at junctures that relate to the child, for instance, feeding them or cleaning their bottom. Comfort is also a motivator that gives a mother the flexibility and freedom to continue with her activities. The motivators of hand washing with soap in a school context among others include, justification where there is need to wash away germs that cause disease. This was drawn from the fact that hand washing is covered in the syllabus. Fun as a motivational factor states that hand washing with soap was found to be fun and provided a form of play for the children. This is not a sustainable motivator in the long run but can work at the initial stages of the campaign Fitting in also involves washing hands after using the toilet and is the accepted code of conduct in school. The presence of other children washing hands acted as a trigger to hand washing.

\subsubsection{Awareness}

According to Murray \& Lopez, (1997) awareness campaigns on hand washing with soap programme to be emphasized to target groups such as the general public where most become more aware of the benefits of hand washing with soap in order to foster behavior change at the necessary scale. Business people also to be encouraged to understand the potential commercial benefits of a nation of people using soap instead of just water to wash their hands. They should be encouraged to lend their marketing expertise to this public health goal. Academics, who do research on topics relevant to hand washing with soap, including water supply and sanitation topics, should be encouraged to publish research findings in popular media, as well as opinion pieces supporting global hand washing day. Celebrities such as Global hand washing day planners should consider recruiting popular culture celebrities from music, sports, film and television to help carry global hand washing day messages. To get them to agree to this, these stars must be convinced that hand washing with soap is an issue worthy of their time and attention. Religious Leaders as one of the target groups greatly influence public opinion in many communities and should be encouraged to help inform their congregation of the benefits of hand washing and cleanliness before prayer or during other religious rituals, only hands that have been washed 
with soap are truly clean. The health of congregants, particularly the children among them, is unpurified by lack of hand washing with soap. One million lives could be saved each year through hand washing with soap.

Teachers can play a big role in campaigning for hand washing with soap programme. Diarrhea is responsible for the loss of hundreds of millions of school days every year; hand washing with soap can reduce diarrheal diseases by nearly half. The hand washing habit, teachers to teach in school will last a lifetime. They can easily include hand washing with soap in many lessons. Making hand washing stations is a good activity for school children and can influence their families. Also one of the groups to be considered and many people do not realize that hand washing with water alone is not sufficient to make them clean. This information on hand washing benefits and prevalence is an underreported story today. These are the people who can put in the media hand washing with soap messages for publicity, Rabie \& Curtis (2006),

Health Community also need to sensitized and emphasized on hand washing with soap as it is among the most effective ways to prevent diarrheal diseases and pneumonia which together are responsible for the majority of child's death. Every year more than 3.5millionchildren do not live to celebrate their fifth birthday because of diarrhea and pneumonia. Hand washing can also prevent skin infections, eye infections, intestinal worms and benefits of people living with HIV/AIDS. Hand washing is effective in preventing the spread of diseases even in overcrowded and highly contaminated slum environment. Children are a special group which should be considered in this campaign. Children feel cool and fun to wash their hands with soap. Washing hands with soap makes the germs go away. They can also be like teachers in their family about hand washing with soap. UNICEF, state of the word's children. (2008).

NGO understands motivations for and barriers to hand washing with soap are the first step towards promoting behavior change, they are well placed to understand what motivates their constituencies. Diarrhea epidemics can jeopardize projects and undo years of work, healthy people can better capitalize on Social and Economic interventions. Community or Traditional Leaders can also make a difference in their community by organizing hand washing programs for all members and leading change to set up hand washing stations in homes and schools. The benefits of hand washing with soap and other hygiene improvements will only come if the community works together as one, if only a few participate, the effect will be small and the community will miss an opportunity to distinguish itself.

Researches done by other researchers include the Power of Primary Schools to change and Sustain hand washing with Soap among children, the Cases of Vietnam and Peru. Authors were Pennelope, Dutton, Rocio, Florez, Peschiera, and Nga Kim Nguyen inSeptember2011. Method used was formative. The Global Hand washing scaling up Project encourages the development of innovative effective approaches to hand washing promotion. Unlike previous hygiene initiatives in Vietnam, the HWI undertook in-depth research of children's hand washing behavior in the order to understand what influenced their behavior and design appropriate campaigns based on research findings. WSP commissioned an independent team of international and local consultants to carry out field research to learn about lives of primary school children and the school and home context where hand washing promotion will take place. Gaining an insight into the minds and realities of primary school children would help to better understand the barriers and motivations to washing hands with soap. The research also sought to understand the larger context of the children's world, including social dynamics, roles and responsibilities of teachers, a typical day in the life of a child (during the school term and holiday time), and their access to water, sanitation and soap, Rabie\& Curtis (2006),

Aware of the difficulties of obtaining information from very young children, WSP focused the research on children from grades four and five (9-10 years old), although younger children (grades 2-3) were included in one research exercise. Six primary schools, chosen from three provinces to represent northern, central, and southern regions of Vietnam, took part in the formative research. Each province included one peri-urban and one rural school. Research tools included games and fun activities to encourage the children's active participation and interest.

A total of 30 students (boys and girls), divided into groups of about five students from each school, used each of the research tools, with the exception of the Motivator Pictures exercise story telling based on pictures about hand washing where younger children joined in. Eighteen Students took part in the Belief Interviews that were followed up with observations of sanitation and hand washing facility in their homes and interviews with their caretaker Formative search helped identify opportunities for school points of contact with children. Studying the daily schedule, researchers were able to find out if children played together in the school yard after school, or whether there was opportunity for contact at night through mass media. When children indicated they watched television, researcher prompted them for more information about what shows they watched and why?

\subsubsection{Study Findings on Hand washing Behavior in Kenya}

Overcrowding at the hand washing facilities where there is limited hand washing facilities to cater for the school population leading to pushing around the facilities. This is a barrier for pupils in lower primary 
classes and for girls. Soap disappearance and wastage in schools that had tried this initiative raised this as the greatest challenge that the initiative faced. Poor or lack of water drainage of hand washing facilities which lead to accumulation of dirty water in the trough and spilling around the hand washing site. As a result, the hand washing facilities become muddy and discourage children from washing hands. Bars of soaps fall into the muddy water or disappear in the trough. Lack of support from teachers in some schools such an intervention is perceived as an additional workload for teachers who feel they are already overworked. After the introduction of free primary education, the work load for teachers increased drastically. Any additional tasks are likely to face resistance from teachers.

Lack or cost of soap is perceived to be expensive and not catered for in the school budget allocations. Currently, parents believe that primary education is free and it would face a challenge to ask for contributions from them. This is in spite of the fact that parents also attach value to soap as indicated by 58 percent of the children (source: pre-evaluation forms) who said that parents remind them to take care of soap because it is expensive. It is expensive and sometimes one may not be able to afford it. Sometimes the handling of soap is a problem if any amount is put at the water. Lack of consistent water supply in most schools is also a challenge. Other chores are thus likely to take precedence over hand washing because of such a scarcity. Some schools rely on water supply from vendors, whose source is not trusted. In instances where

Diesel-powered water tanks are used, the constant supply of fuel becomes a challenge. Resistance by teachers because of behavior trial which experienced resistance by some teachers and head teachers in some schools, especially in the cities. In other schools teachers reserved the right to keep the soap for their use. Some headmasters were not in favor of the idea of soap introduction as they felt it would be a waste of time. Resistance by teachers was driven by their perception of this being an addition to their workload and possible challenges in sustaining the supply of soap in school. UNICEF state of world's children. (2008)

\subsection{Critique of literature review.}

Hand washing with soap is a cornerstone of public health, and new hygienic behavior and sanitary services were principal drivers of the sharp drop in deaths from infectious diseases in affluent countries in the late 19th century. Along with the isolation and safe disposal of feces and the provision of adequate amounts of clean water, hand washing with soap is one of the most effective ways to prevent diarrheal diseases. It is also the cheapest way. In addition, hand washing with soap can limit the transmission of respiratory diseases, the largest killer of children under five. And hand washing with soap is also a formidable in efforts to combat a host of other illness, such as helminthes these (worms) eye infections like trachoma and skin infection like impetigo.

Primary school-going children are considered a special target group. Since habits acquired while one is young are likely to be carried over to adulthood, intervention in hand washing behavior would have a ripple effect for future generations. Hand washing with soap is part of the concept of hygiene, which forms part of the social studies syllabus in primary schools. Children spend most of their active hours in a school environment and may also have different motivators and barriers to hand washing.

\subsection{Summary}

Hands are the principal carriers of disease-causing germs and it is important to ensure that people have a way to wash their hands at these critical moments. Simple, low-cost solutions like Tippy Taps are within the financial and technological reach of even the poorer communities. Hand washing with soap is the single most cost-effective health intervention. Hand washing promotion is cost-effective when compared with other frequently founded health interventions A $\$ 3.35$ investment in hand washing brings the same health benefits as an \$11.00 investment in latrine construction, a \$200.00 investment in household water supply, and an investment of thousands of Dollars in immunization investment in the promotion of hand washing with soap can also maximize the health benefits of investments in water supply and sanitation infrastructure and reduce health risks when families do not have access to basic sanitation and water supply services.

Cost is not typically a barrier to hand washing promotion: almost all households in the world already have soap-though it is commonly used for laundry, dishwashing, and bathing rather than for hand washing. When it comes down to changing good hygiene practices, children, the segment of society so often the most energetic, enthusiastic and open to new ideas - can act as agents of change by taking the hand washing lessons 'learned at school back into their homes and communities. The active participation and involvement of children - ideally situated at the intersection of the home, school and community-based intervention. Children spend most of their active hours in a school environment and may also have different motivators and barriers to hand washing. Global Hand washing Day aims at motivating children (Healthy Schools Health People HSHP).Due to the importance of hand washing with soap, "WHO" came up with a "GLOBAL HANDWASHING DAY" which was first launched on 15th October 2009 and since that time all countries commemorate 15th October every year as a Global hand washing day World Wide, Countries are celebrating Global Hand washing Day where several activities take place including hand washing with soap campaign in 
school, and villages. Demonstration on hand washing activities in the same places. The challenge is to transform hand washing with soap from abstract good ideas into an automatic behavior performed in homes, schools and communities worldwide. More hand washing with soap would make a significant contribution to meeting the Millennium Development Goal of reducing deaths among children under the age of five by two thirds by 2015. Fewtwell et al (2005).

\subsection{Research gap.}

Researches done by other researchers include the Power of Primary Schools to change and Sustain hand washing with Soap among children, the Cases of Vietnam and Peru. Authors were Pennelope, Dutton, Rocio, Florez, Peschiera, and Nga Kim Nguyen inSeptember2011. Method used was formative. The Global Hand washing scaling up Project encourages the development of innovative effective approaches to hand washing promotion. Unlike previous hygiene initiatives in Vietnam, the HWI undertook in-depth research of children's hand washing behavior in the order to understand what influenced their behavior and design appropriate campaigns based on research findings. WSP commissioned an independent team of international and local consultants to carry out field research to learn about lives of primary school children and the school and home context where hand washing promotion will take place. Gaining an insight into the minds and realities of primary school children would help to better understand the barriers and motivations to washing hands with soap. The research also sought to understand the larger context of the children's world, including social dynamics, roles and responsibilities of teachers, a typical day in the life of a child (during the school term and holiday time), and their access to water, sanitation and soap. Curtis \& Scott (2007).

The researches done did not address challenges facing uptake of hand washing with soap programme in schools and my study is meant to capture the same. Primary school-going children are considered a special target group. Since habits acquired while one is young are likely to be carried over to adulthood, intervention in hand washing behavior would have a ripple effect for future generations. Hand washing with soap is part of the concept of hygiene, which forms part of the social studies syllabus in primary schools. Children spend most of their active hours in a school environment and may also have different motivators and barriers to hand washing. When it comes down to changing good hygiene practices, children, the segment of society so often the most energetic, enthusiastic and open to new ideas - can act as agents of change by taking the hand washing lessons 'learned at school back into their homes and communities. It means then if these challenges will not be addressed, then promoting hand washing with soap programme in schools will still be a challenge.

\subsection{Introduction}

\section{Research Methodology}

There is an inextricable link between theories, methods and methodologies in the research process. Bentzon et al, (1998). Methodologies refer to the approaches undertaken in the field to prove or disapprove the initial assumptions whereas the research methods are the techniques employed to gather desired data from the target group of the present study. This chapter shall give a clear picture on my research journey with an emphasis on the methodological approaches employed and the accompanying methods of data collection and data analysis.

\subsection{Research design.}

According to Burns and Groove, (2003) a research design is a blue print for conducting a study with maximum control over factors that may interfere with the validity of the findings. The research design articulates what data was required, what methods were used to collect and analyze this data, and how all of was going to answer the research question. Design is a logical task undertaken to ensure that the evidence collected enables us to answer questions or to test theories as unambiguously as possible.

This research project was a descriptive research. It was purposed to provide an accurate and valid presentation of the factors that pertain to the challenges facing uptake of hand washing with soap programme. A descriptive research is designed to pride a picture of a situation as it naturally happens. Burns \& Grove, (2003). It was useful in justification of current practices, making judgments and further development of theories. For this research project, it was essential to obtain a picture of the hand washing with soap programme in schools and how they can improve their impact through having intensified activities.

\subsection{Study Population}

The target population was public primary schools in Tana Delta Sub County and the target group was550 primary school teachers. $10 \%$ of this population was a representative of this target population. Concentration of this $10 \%$ were teachers in charge of health clubs for schools and this was the population which could tell out the challenges facing uptake of hand washing with soap programme in schools. 


\subsection{Sampling frame}

The researcher drew the sampling frame from Tana Delta public primary schools. The Sub County has a total number of 550teachers and $10 \%$ was a representative of this population which were 55 teachers. The Sub County has 3 administrative divisions namely Tarasaa, Kipini and Garsen respectively. Below is a table 3.1 showing distribution of teachers in the 3 divisions.

Table 3.1 Distribution of schools in Tana Delta Sub-County

\begin{tabular}{llll}
\hline Division & Number of schools & No. of teachers & Sample \\
\hline Tarasaa & 17 & 170 & 17 \\
\hline Kipini & 9 & 90 & 9 \\
\hline Garsen & 28 & 280 & 28 \\
\hline Total & 55 & 550 & 55 \\
\hline
\end{tabular}

\subsection{Sample size and sampling technique.}

A sample is set of individuals selected from the target population and usually is intended to represent the population in a research study (Neumann, 2000). After considering the accuracy factors, desired precision of results, confidence levels and degree of variability, and also considering postulation by Kerlinger, (1973) that sample size of $10 \%$ is large enough as long as it allows for reliable data analysis, this researcher settled at 55 teachers representing $10 \%$ of the study population which was 550 primary school teachers and in so doing, the researcher ensured an equitable distribution along the different schools in the three divisions in Tan Delta Sub County.

\subsection{Data collection instruments}

Data was collected using questionnaires with a set of questions administered by the interviewer to the respondents. The questionnaire was preferred because it is time saving and allowed collection of data from a large sample within a reasonable time frame.

\subsection{Data collection procedure}

Enumerators were briefed by the researcher and taken through the questionnaires and issues clarified. The researcher asked for permission from the District Education Officer of Dana Delta Sub County and agreed on the dates for the exercise. The enumerators visited the schools on the specified dates and conducted the exercise. The questionnaires were administered to the teachers by the enumerators and after filling of the responses, all the questionnaires were submitted to the researcher for analysis and compilation. This exercise took 10 days.

\subsection{Pilot testing}

A pilot study was carried out to 20 respondents who were school health club teachers. This was essential to assess the suitability of the research instrument in terms of validity. These respondents were however not be included in the main research. The questionnaire was research assisted.

\subsection{Data processing and analysis.}

Data was analyzed through the use of SPSS version 20, where both descriptive and inferential statistics such as means, standard deviations and correlations done. The findings are presented in tables and figures and interpretations made.

\subsection{Introduction}

\section{Research Findings And Discussion}

This chapter looked at analyzing the challenges facing uptake of hand washing with soap programme in schools in Tana Delta Sub County. It embodies the presentations, analysis and interpretation of the data collected from teachers from public Public Primary Schools in Tana Delta Sub County. Data was analyzed through the use of SPSS version 20, where both descriptive and inferential statistics such as means and standard deviations were done. The findings were presented in tables and figures and interpretations made.

\subsection{Response rate}

Questionnaire method was used to gather information and the numbers of questionnaires issued were 55 which was the sample size. Out of 55 questionnaires, 52 were returned giving a response rate of $95 \%$. The table below shows the result. 
Table 4.1 Response Rate

$\begin{array}{lll}\text { Number of questionnaires distributed } & \text { Number of questionnaires received } & \text { percentage } \\ 55 & 52 & 95 \%\end{array}$

Out of 55 questionnaires distributed, 52 were received giving a response rate of $95 \%$ meaning that the response rate was accepted. This is evidenced by the number of questionnaires distributed and the ones received back

\subsection{Children perception of dirt}

The study was looking at children perception of dirt. The way children perceive dirt could create an impact on promoting hand washing with soap. The figure 4.1 below shows the study findings on the same.

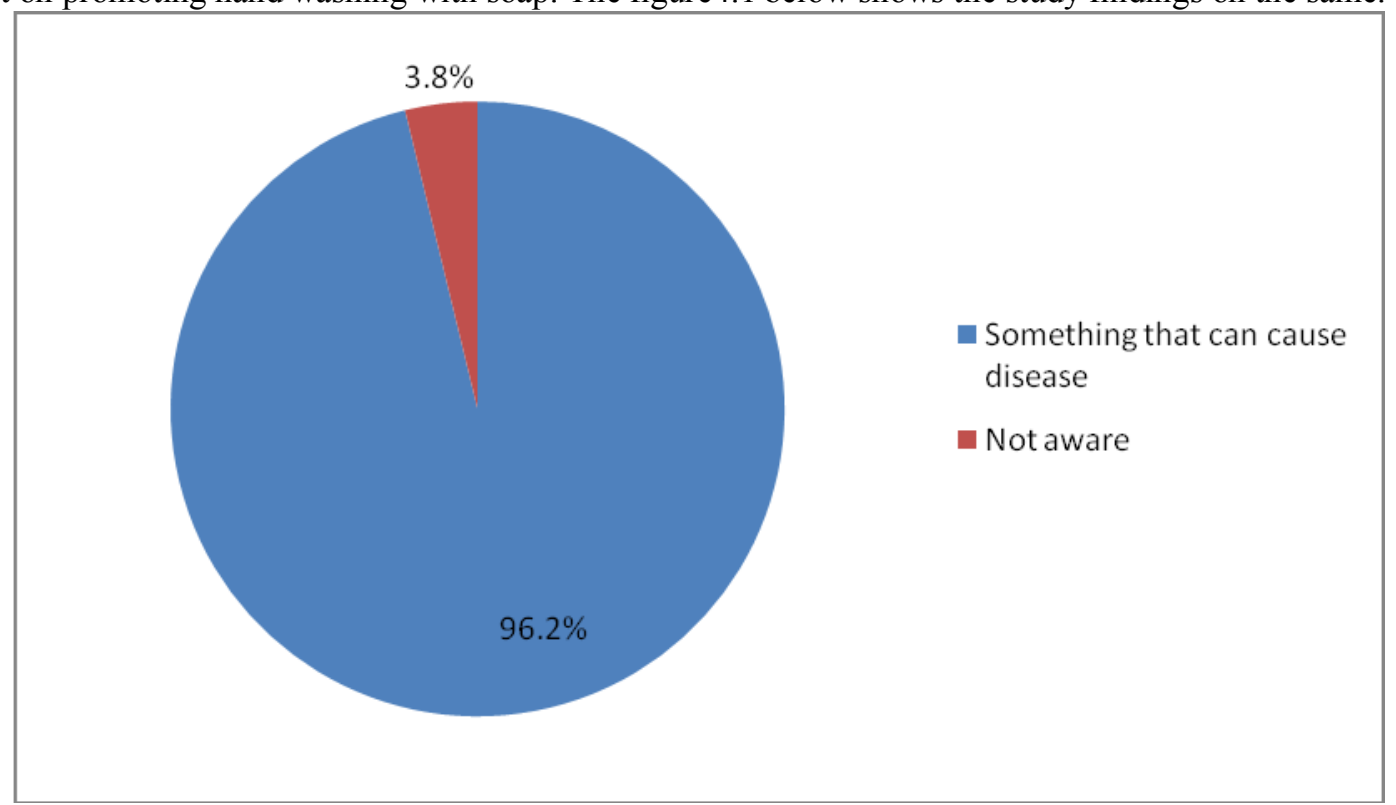

Figure 4.1 Children perception of dirt

From figure 4.1 above, it shows that $96.2 \%$ of the teachers responded that children perceive dirt as something that can cause disease while $3.8 \%$ are not aware. This is a clear indication that sensitization in schools has been done and that the challenges facing uptake of hand washing with soap programme in schools can easily be overcome once emphasis and support of the programme is done. This can easily reduce diarrheal diseases among school going children. The 3.8\% could the schools which had not sensitized their pupils. The $96.2 \%$ being aware does not mean that the programme is being implemented but there are challenges facing uptake of the programme in schools. Perception of dirt will relate the relationship with diseases and hence the practice of hand washing can easily be promoted through mass campaigns and demonstrations in schools. The lessons learnt at schools can easily be taken back home and hence wide spread of knowledge leading to reduction of diarrheal diseases to both school going children and the community at large.

\subsection{Kind of water sources}

The study was looking at kind of water sources available in schools for promoting and sustaining hand washing with soap programme. Hand washing with soap programme in schools can only take off and sustained if there is an available reliable source of water. The table below shows the result findings on the same.

Table 4.2kind of water source

\begin{tabular}{|c|c|c|c|c|c|}
\hline \multicolumn{6}{|c|}{ kind of water sources in school } \\
\hline \multirow{7}{*}{ Valid } & & Frequency & Percent & Valid Percent & Cumulative Percent \\
\hline & Borehole & 19 & 36.5 & 36.5 & 36.5 \\
\hline & Tap water & 8 & 15.4 & 15.4 & 51.9 \\
\hline & Roof catchment & 10 & 19.2 & 19.2 & 71.2 \\
\hline & Well & 10 & 19.2 & 19.2 & 90.4 \\
\hline & Others( specify) & 5 & 9.6 & 9.6 & 100.0 \\
\hline & Total & 52 & 100.0 & 100.0 & \\
\hline
\end{tabular}

From table 4.2 above, $36.5 \%$ schools have boreholes, $19.2 \%$ have roof catchment, $19.2 \%$ well, $15.4 \%$ tap water and 9.6 others. This indicates that schools have at least a water source though not reliable to sustain this hand washing with soap programme. Recharging of these water sources is seasonal hence shortage of the 
same during dry season. The schools with roof catchment have only one tank each of 10,000 cubic metres which cannot harvest water from the whole roof surface meaning most it goes to waste because the size of the tank is small compared to the roof surface. Water is still a problem in most schools. Tap water is more reliable because there is a permanent river passing through the Sub County to the Indian Ocean though only 15.4\% of the schools have tap water.

\subsection{Water adequacy}

The study was looking at the adequacy of the available water source in schools for implementation and sustaining of hand washing with soap programme. This programme can only take off and sustained if there is enough water in schools but if not enough then the challenge of sustaining it will still be experienced. The table below shows the result findings on water adequacy.

\begin{tabular}{llllll}
\multicolumn{6}{l}{ Table 4.3 water adequacy } \\
\hline \multirow{4}{*}{ Valid } & Frequency & Percent & Valid Percent & Cumulative Percent \\
& No & 30 & 57.7 & 57.3 & 57.7 \\
& Yes & 22 & 42.3 & 42.3 & 100.0 \\
& Total & 52 & 100.0 & 100.0 & \\
\hline
\end{tabular}

From table 4.4 above, $57.7 \%$ responses indicate that water is not enough for school hygienic practices while $47.3 \%$ responses indicate that water is enough. Water adequacy in schools is the determining factor to starting and sustaining hand washing with soap programme in schools.

\subsection{Soapprovision}

The study was looking at soap provision in schools for hand washing. Hands can only be clean and safe if soap is used. Pathogenic organisms can only be detached from hands by the use of soap. Hand washing with soap programme in schools can only be achieved in there is soap provision in schools. The figure below show the result findings on soap provision in schools

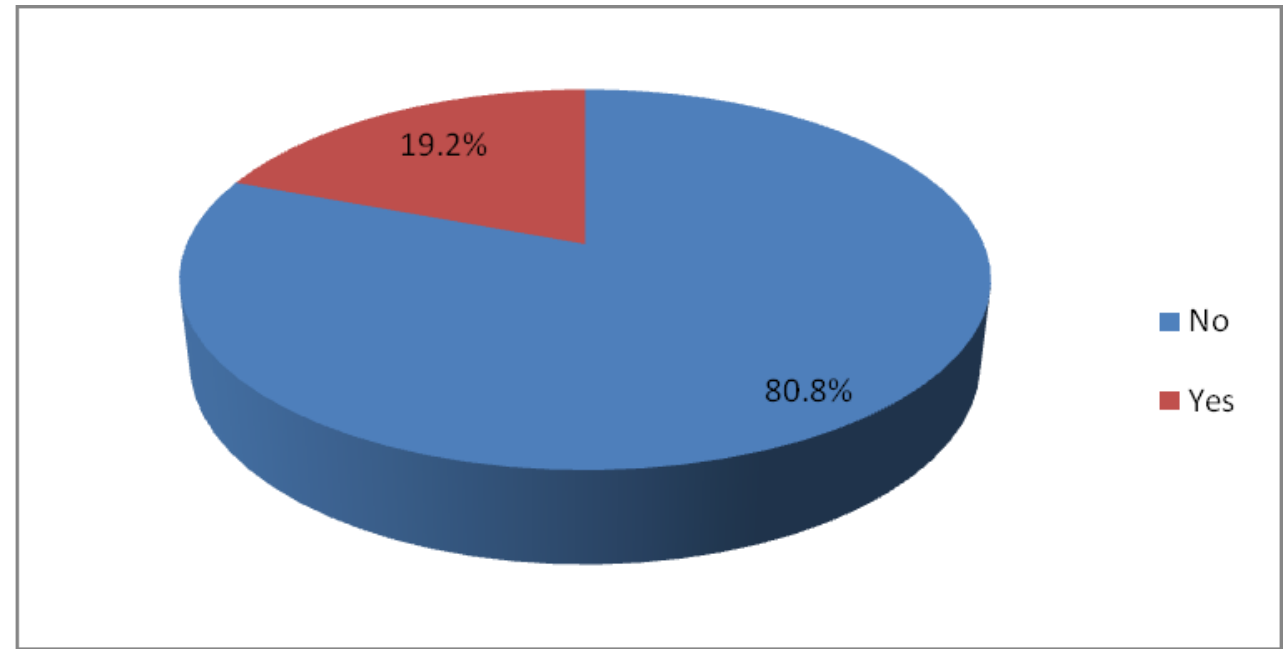

Figure 4.2 soap provision for hand washing in schools

This figure 4.2 shows that $80.8 \%$ of the schools are not provided with soap for hand washing. Soap is the key component for effective hand washing to reduce diarrheal diseases. This means the programme has not picked up because of lack of soap for hand washing. 19.2\% are the only schools provided with soap for hand washing. To achieve reduction of diarrheal diseases among school going children, soap provision and use in schools for hand washing has to be done. Hand washing with soap has to be done at four critical moments in order to achieve diarrheal disease reduction among school going children.

\subsection{Meaning of hand washing with soap}

The study was looking at the respondents' level of understanding on the meaning of hand washing with soap. Knowing the meaning and relating it with disease prevention will create an impact on promoting hand washing with soap in schools. The figure 4.3 below shows the result findings on the same. 


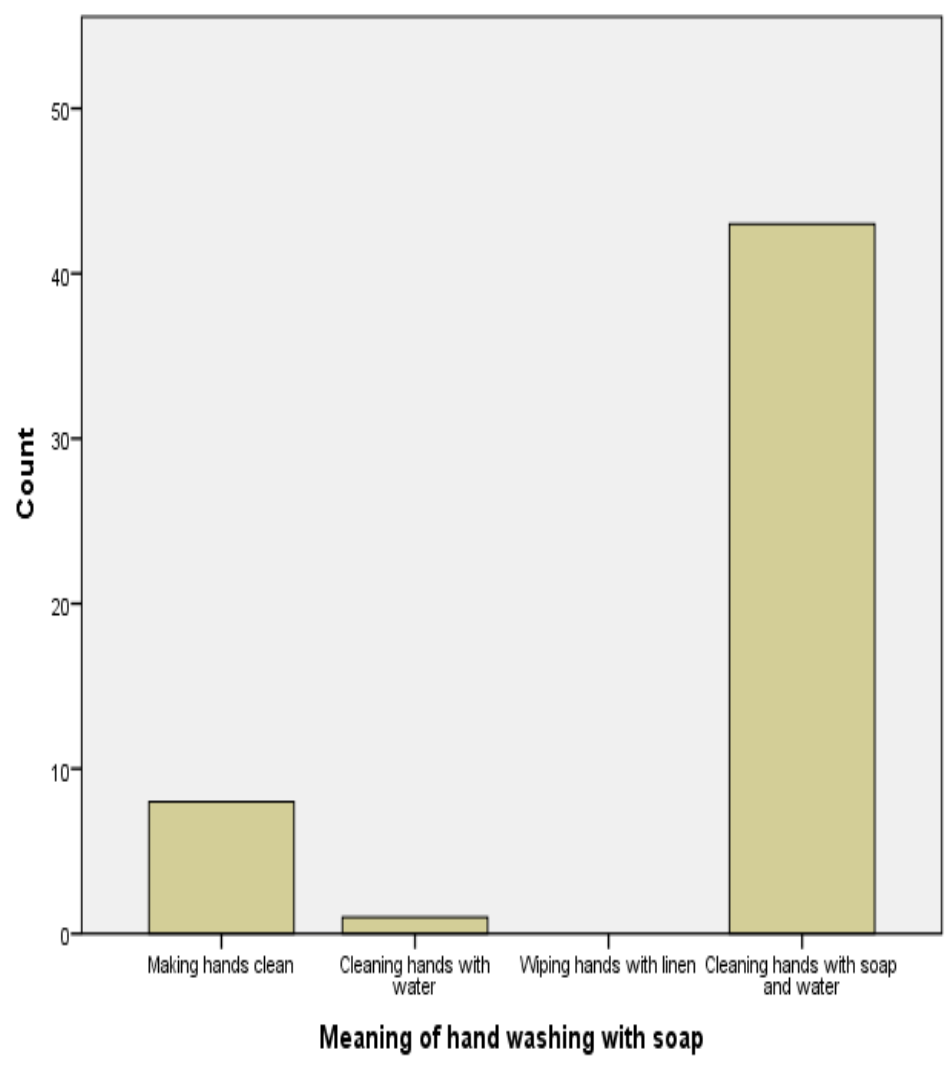

Figure 4.3Meaning of hand washing with soap

From Figure 4.3 above, $82.7 \%$ responded that hand washing with soap is the cleaning of hands

With soap and water while $15.4 \%$ responded that it is cleaning of hands with water. Because meaning of hand washing with soap is known, then it is only required to overcome the challenges facing uptake of the programme in order to upscale the programme widely for it to gain support and sustainability because of its benefits.

The respondents were the teachers responsible for health clubs and if they get the concepts of hand washing with soap in schools, it becomes easier for this programme to take off and be sustained because they will be the ones spearheading the programme.

\subsection{School children risky hygiene practice}

This study was looking at school children risky hygiene practice. This would create an impact on promotion of hand washing with soap because of relationship between dirty hands and disease causing germs. The table below shows the result findings on the same.

Table 4.4 School children risky hygienic practices

\begin{tabular}{|c|c|c|c|c|c|}
\hline \multirow{4}{*}{ Valid } & & Frequency & Percent & Valid Percent & Cumulative Percent \\
\hline & $\begin{array}{l}\text { Eating without washing hands, } \\
\text { washing hands after visiting } \\
\text { toilet, sucking of fingers, }\end{array}$ & $\begin{array}{l}\text { not } \\
\text { the51 }\end{array}$ & 98.1 & 98.1 & 98.1 \\
\hline & Cleaning the toilet & 1 & 1.9 & 1.9 & 100.0 \\
\hline & Total & 52 & 100.0 & 100.0 & \\
\hline
\end{tabular}

From the above table. $98.1 \%$ of the teachers responded that the school children risky hygienic practices are eating without washing hands, not washing hands after visiting the toilet and sucking of fingers while $1.9 \%$ responded that it is cleaning the toilet. If school children risky hygienic practices are known, then it becomes easier for teachers to sensitize them on the importance of washing hands with soap at four critical moments so as to reduce diarrheal diseases among school going children. Knowledge about risks would encourage the teachers to promote hand washing with soap programme in schools in order to reduce diseases brought about by use of contaminated hands

4.8 motivational factors to hand washing with soap in schools 
This study was looking at the motivational factors to hand washing with soap in schools. The relationship between motivational factors and importance of hand washing plays a role in promotion of hand washing soap. If motivational factors do not relate with the importance of hand washing with soap, then it will be the right time for vigorous sensitization sessions coupled with demonstrations in schools to be done. The figure 4.5 below shows the result findings on the same.

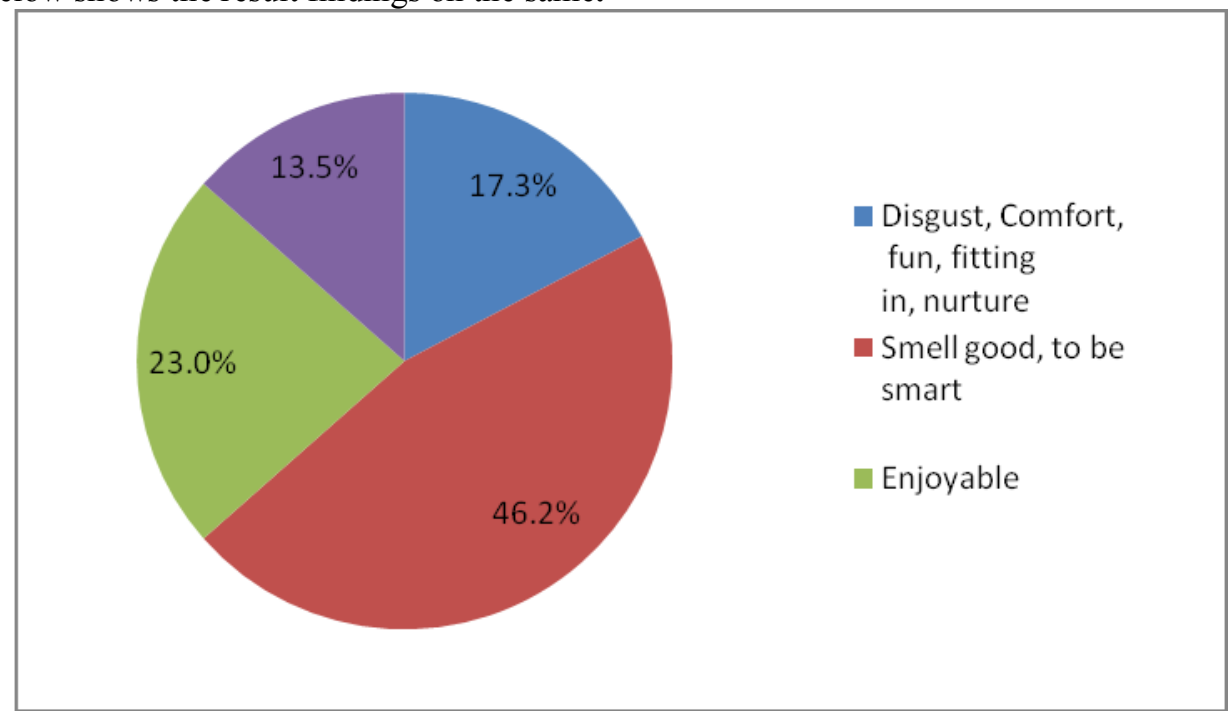

Figure 4.4 Motivational factors to hand washing with soap

From the above figure, $46.2 \%$ responded that the motivational factors to hand washing are smelling good and to be smart, $23 \%$ enjoyable, $17.3 \%$ include disgust, comfort, fun and nurturing while $13.5 \%$ not applicable. Motivational factors should have a relationship with disease prevention if hand washing with soap is to be promoted in schools. From the findings, it has been realized that smelling good and being smart has the highest score of $46.2 \%$ which has no relationship with importance of hand washing. This means that a lot is required to be done in terms sensitization for motivational factors to be in line with importance of hand washing with soap and diarrheal disease prevention.

\subsection{School children awareness of the importance of hand washing with soap.}

This study was looking at the school children awareness on the importance of hand washing with soap. If there is awareness among school going children, then implementation, practice, sustainability and reduction of diarrheal diseases will be achieved hence healthy school community. The table below shows the result findings.

Table 4.5School children awareness of the importance of hand washing with soap

\begin{tabular}{llllll}
\hline & & Frequency & Percent & Valid Percent & Cumulative Percent \\
Valid & Yes & 47 & 90.4 & 90.4 & 90.4 \\
& No & 5 & 9.6 & 9.6 & 100.0 \\
\hline
\end{tabular}

From table 4.5 above, $90.4 \%$ of the respondents said that children are aware of the importance of hand washing with soap while 9.6 are not aware of the importance of hand washing with soap. This is indicative that school children have knowledge about hand washing with soap and it is only emphasis and implementation that is required to be done so long as the challenges facing uptake of the programme are handled.

\subsection{Start of hand washing with soap programme in schools}

The study was looking at whether the hand washing with soap programme started in schools. This was to give a clear picture of the status, progress and challenges facing uptake of the same. The table below shows the findings of the study.

Table 4.6 start a hand washing with soap programme in Schools

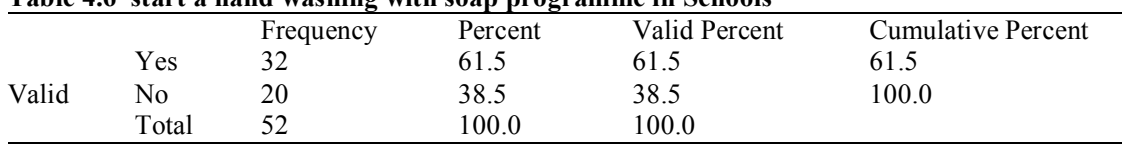


From the table 4.10 above, $65.5 \%$ of the respondents indicated that they started hand washing with soap programme in schools, while $38.5 \%$ had not yet. The school which started should sustain the programme and the ones not yet should be able to do so. This will enable the programme pick and spread at the village level through school children. Diarrheal diseases will be reduced among school going children through implementation of the strategy.

\subsection{Progress of programme in schools}

The study looked at the progress of the programme in schools for the ones which had started. This was to give a clear picture of how the programme is moving on in schools. This would also give a basis of achievements or challenges facing the programme. The table below shows the findings.

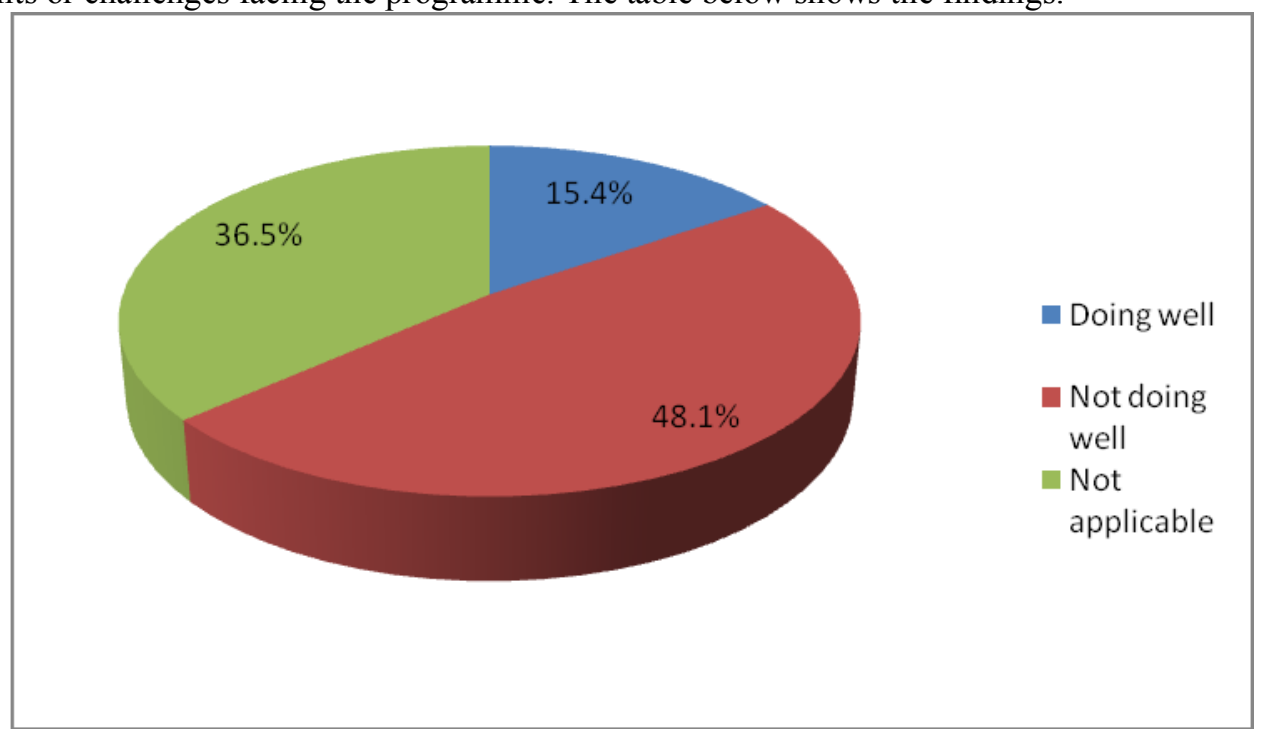

Figure 4.5 progress of the programme in schools

From figure $4.5 \mathrm{above}$, it shows that $48.1 \%$ responded that the programme is not doing well, $15.4 \%$ doing well and 36.5 not applicable. This indicates that the programme was rolled out but not picking up due to challenges facing the programme. Findings also indicate that some schools had not yet started at all. This progress will now be able to link up with the challenges facing uptake of the programme for diarrheal disease control.

\subsection{Challenges of the programme}

The study looked at the challenges facing uptake of the programme. This was to enable know the hindrances of the progress of the programme hence come up with recommendations and suggestion which when implemented can bring positive change towards success and reduction of diarrheal diseases. The table below shows the findings.

Table 4.7 challenges of the programme

\begin{tabular}{llllll}
\hline & & Frequency & Percent & Valid Percent & Cumulative Percent \\
& Soap disappearance & 2 & 3.8 & 3.8 & 3.8 \\
& $\begin{array}{l}\text { Disappearance of } \\
\text { Valid }\end{array}$ & hand & washing & & 17.3 \\
& facilities & 21 & 13.5 & 13.5 & 57.7 \\
& Not Applicable & 22 & 40.4 & 40.4 & 100.0 \\
& No provision of soap & 52 & 42.3 & 42.3 & 100.0 \\
& Total & 100.0 & & \\
\hline
\end{tabular}

From table4.7 above, $42.3 \%$ responded that lack of soap provision in schools appears to affect the programme, $40.4 \%$ for none starters due to challenges and $3.8 \%$ soap disappearance. Hand washing with soap programme cannot start if soap is not available because it will be meaningless and the objective cannot be achieved.

\subsection{Support of the programme by the head teacher and the entire staff}

This study looked at the support of the programme by both the head teacher and the entire staff. For success of any programme in a school, it must win support from the entire staff otherwise it will be bound to fail. Findings are shown in figure 4.6 below. 


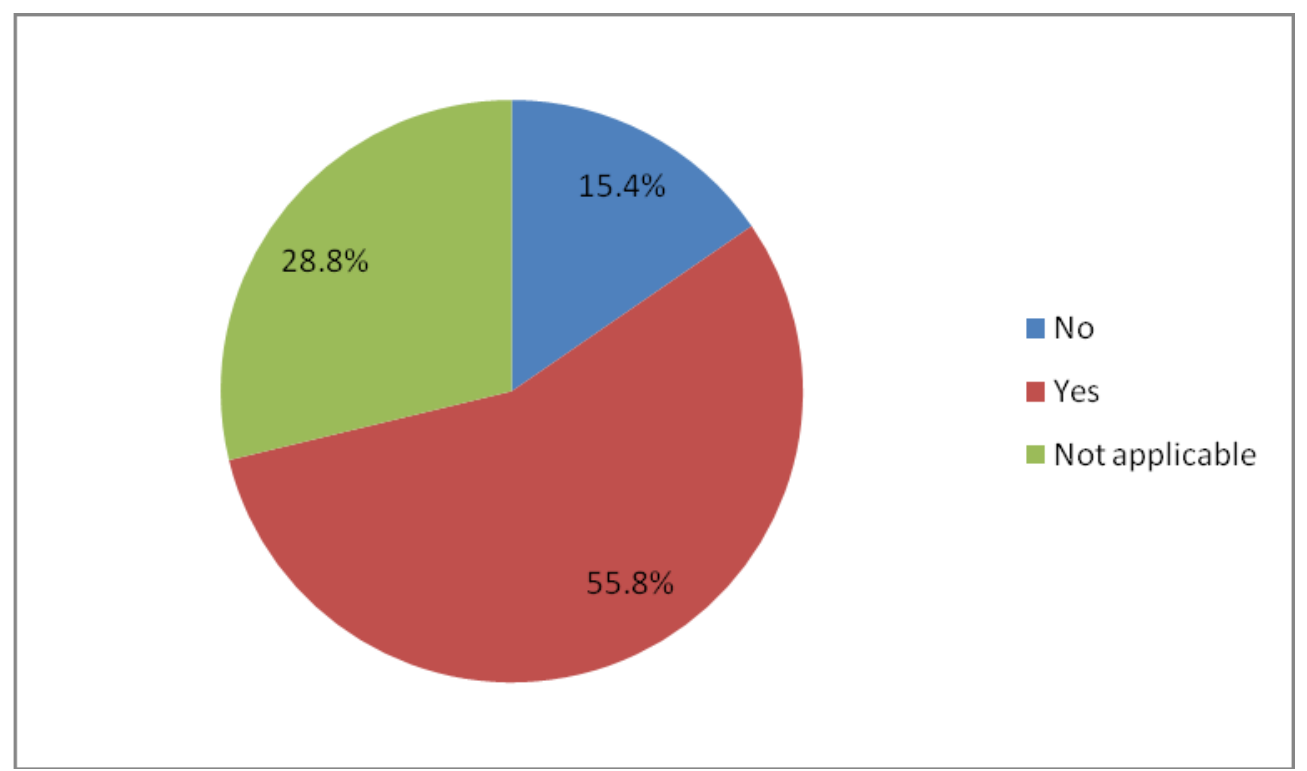

Figure 4.6 Support of programme by the Head teacher and the entire staff

From figure 4.8 above, $55.8 \%$ of the respondents meant that the programme is supported by the head teacher and the entire staff. Despite the support, there is still a challenge of soap provision, water adequacy and hand washing facilities. $15.4 \%$ meant that the programme is not supported while $28.8 \%$ of the respondents meant that the programme had not started in their respective schools.

\subsection{Introduction}

\section{Summary, Conclusion and Recommendations}

This chapter summarizes the results of the findings and valid conclusions are drawn on the challenges facing uptake of hand washing with soap programme in schools in Tana Delta s Sub County. The researcher also offers recommendations for overcoming the challenges and hindrances to the implementation of the programme based on the literature and the four independent variables that form the construct upon which this study was developed. .

\subsection{Summary}

Hand washing with soap and water is among the most effective and inexpensive way to prevent diarrheal diseases and pneumonia which together are responsible for the majority of child deaths. This behavior is projected to become a significant contribution to meeting the Millennium Development friction Goal of reducing death among children under the age of five by two thirds by 2015 . October 15 has been appointed to become Global Hand washing Day in accordance with year 2008 as the International Year of Sanitation by the United Nations. Hands always act as the vectors that carry disease causing pathogens from person to person, either through direct contact or indirect via surfaces

The focus of this research project was to analyze the challenges facing uptake of hand washing with soap programme in schools in Tana Delta Sub County. Premised on, this research was guided by specific objectives which include understanding children's perception of dirt, to understand the risky hygiene practices of children, to identify children motivational factors and children awareness on the importance of hand washing with soap. The research project was conducted in Tana Delta Sub County. It applied descriptive design of research. The target population was 550 respondents but $10 \%$ of the population was a representative of the study population which was 55 respondents. Data was collected using questionnaires. Collected data was organized in terms of variables and each response counted. Data was analyzed and findings presented in form of graphs, pie chart, tables and continuous prose in explanations. This research project formulated some recommendations which when implemented will upscale uptake of hand washing with soap programme in schools.

The way children perceive dirt could create an impact on promoting hand washing with soap. The study findings on the same showed that $96.2 \%$ of the teachers responded that children perceive dirt as something that can cause disease while $3.8 \%$ are not aware. This is a clear indication that sensitization in schools has been done and that the challenges facing uptake hand washing with soap programme in schools can easily be overcome once emphasis and support of the programme is done. This can easily reduce diarrheal diseases among school going children. The $3.8 \%$ could the schools which had not sensitized their pupils. The 
96.2\% being aware does not mean that the programme is being implemented but there are challenges facing uptake of the programme in schools. Perception of dirt will relate the relationship with diseases and hence the practice of hand washing can easily be promoted through mass campaigns and demonstrations in schools. The lessons learnt at schools can easily be taken back home and hence wide spread of knowledge leading to reduction of diarrheal diseases.

Kind of water sources available in schools for promoting and sustaining hand washing with soap programme matter a lot .Hand washing with soap programme in schools can only take off if there is an available reliable source of water. The study findings indicatedthat $36.5 \%$ schools have boreholes, $19.2 \%$ have roof catchment, $19.2 \%$ well, $15.4 \%$ tap water and 9.6 others. This indicates that schools have at least a water source though not reliable to sustain this hand washing with soap programme. Recharging of these water sources is seasonal hence shortage of the same during dry season. The schools with roof catchment have only one tank each of 10,000 cubic meters which cannot harvest water from the whole roof surface meaning most it goes to waste because the size of the tank is small. Water is still a problem in most schools. Tap water is more reliable because there is a permanent river passing through the Sub County to the Indian Ocean though only $15.4 \%$ of the schools have tap water.

Adequacy of available water source in schools for implementation and sustaining of hand washing with soap programme is a key factor. This programme can only take off and sustained if there is enough water in schools but if not enough then the challenge of sustaining it will still be experienced. The findings showed that $57.7 \%$ responses indicate that water is not enough for school hygienic practices while $47.3 \%$ responses indicate that water is enough.

Soap provision in schools for hand washing is very important. Hands can only be clean and safe if soap is used. Pathogenic organisms can only be detached from hands by the use of soap. Hand washing with soap programme in schools can only be achieved in there is soap provision in schools. The findings on soap provision in schools showed that $80.8 \%$ of the schools are not provided with soap for hand washing. Soap is the key component for effective hand washing to reduce diarrheal disease. This means the programme has not picked up because of lack of soap for hand washing. 19.2\% are the only schools provided with soap for hand washing. To achieve reduction of diarrheal diseases among school going children, soap provision and use in schools for hand washing has to be done. Hand washing with soap has to be done at four critical moments in order to achieve diarrheal disease reduction among school going children.

The respondents' level of understanding on the meaning of hand washing with soap is very important. Knowing the meaning and relating it with disease prevention will create an impact on promoting hand washing with soap in schools. The findings on the same indicated that $82.7 \%$ responded that hand washing with soap is the cleaning of hands with soap and water while $15.4 \%$ responded that it is cleaning of hands with water. Because meaning of hand washing with soap is known, then it is only required to overcome the challenges facing uptake of the programme in order to upscale the programme widely for it to gain support and sustainability because of its benefits. The respondents were the teachers responsible for health clubs and if they get the concepts of hand washing with soap in schools, it becomes easier for this programme to take off and be sustained because they will be the ones spearheading the programme.

School children risky hygiene practice is also another area that was considered in my research project. This would create an impact on promotion of hand washing with soap because of relationship between dirty hands and disease causing germs. The findings of the of the study indicated that $98.1 \%$ of the teachers responded that the school children risky hygienic practices are eating without washing hands, not washing hands after visiting the toilet and sucking of fingers while $1.9 \%$ responded that it is cleaning the toilet. If school children risky hygienic practices are known, then it becomes easier for teachers to sensitize them on the importance of washing hands with soap at four critical moments so as to reduce diarrheal diseases among school going children. Knowledge about risks would encourage the teachers to promote hand washing with soap programme in schools in order to reduce diseases brought about by use of contaminated hands.

Motivational factors to hand washing with soap in schools was an area that also looked into. The relationship between motivational factors and importance of hand washing plays a role in promotion of hand washing soap. If motivational factors do not relate with the importance of hand washing with soap, then it will be the right time for vigorous sensitization s. The findings on this study showedthat $46.2 \%$ responded that the motivational factors to hand washing are smelling good and to be smart, $23 \%$ enjoyable, $17.3 \%$ include disgust, comfort, fun and nurturing while $13.5 \%$ not applicable. Motivational factors should have a relationship with disease prevention if hand washing with soap is to be promoted in schools. From the findings, it has been realized that smelling good and being smart has the highest score of $46.2 \%$ which has no relationship with importance of hand washing. This means that a lot is required to be done in terms sensitization for motivational factors to be in line with importance of hand washing with soap and diarrheal disease prevention.

School children awareness on the importance of hand washing with soap is an area considered in the study. If there is awareness among school going children, then implementation, practice, sustainability and 
reduction of diarrheal diseases will be achieved hence healthy school community. The findings of the study indicated that $90.4 \%$ of the respondents said that children are aware of the importance of hand washing with soap while 9.6 are not aware of the importance of hand washing with soap. This is indicative that school children have knowledge about hand washing with soap and it is only emphasis and implementation that is required to be done so long as the challenges facing uptake of the programme are handled.

The study looked at whether the hand washing with soap programme started in schools. This was to give a clear picture of the status, progress and challenges facing uptake of the same. The findings showed that $65.5 \%$ of the respondents indicated that they had started hand washing with soap programme in schools, while $38.5 \%$ had not yet. The schools which started should sustain the programme and the ones not yet should be able to do so. This will enable the programme pick and spread at the village level through school children. Diarrheal diseases will be reduced among school going children through implementation of the strategy.

The study also looked at the progress of the programme in schools for the ones which had started. This was to give a clear picture of how the programme is moving on in schools. This would also give a basis of achievements or challenges facing the programme. Study findings showed that $48.1 \%$ responded that the programme was not doing well, $15.4 \%$ doing well and 36.5 not applicable. This indicates that the programme was rolled out but not picking up due to challenges facing the programme. Findings also indicate that some schools had not yet started at all. This progress will now be able to link up with the challenges facing uptake of the programme for diarrheal disease control.

Challenges facing uptake of the programme was another area of concern. This was to enable know the hindrances of the progress of the programme hence come up with recommendations and suggestion which when implemented can bring positive change towards success and reduction of diarrheal diseases. The findings showed that $42.3 \%$ responded that lack of soap provision in schools appears to affect the programme, $40.4 \%$ for none starters due to challenges and 3.8\% soap disappearance. Hand washing with soap programme cannot start if soap is not available because it will be meaningless and the objective cannot be achieved.

The study also looked at the support of the programme by both the head teacher and the entire staff. For success of any programme in a school, it must win support from the entire staff otherwise it will be bound to fail. The findings indicated that $55.8 \%$ of the respondents meant that the programme is supported by the head teacher and the entire staff. Despite the support, there is still a challenge of soap provision, water adequacy and hand washing facilities. $15.4 \%$ meant that the programme is not supported while $28.8 \%$ of the respondents meant that the programme had not started in their respective schools.

\subsection{Conclusion}

Hands often act as vectors that carry disease-causing pathogens from person to person, either through direct contact or indirectly via surfaces. Humans can spread bacteria by touching other people's hand, hair, nose, and face. Hands that have been in contact with human or animal feces, bodily fluids like nasal excretions, and contaminated foods or water can transport bacteria, viruses and parasites to unwitting hosts. Hand washing with soap works by interrupting the transmission of disease. Washing hands with water alone is significantly less effective than washing hands with soap in terms of removing germs. Although using soap in hand washing breaks down the grease and dirt that carry most germs, using soap also means additional time consumed during the massaging, rubbing, and friction to dislodge them from fingertips, and between the fingers, in comparison with just using water for hand washing. Effective hand-washing with soap takes $8-15$ seconds, followed by thorough rinsing with running water. Primary school-going children are considered a special target group, since habits acquired while one is young are likely to be carried over to adulthood; intervention in hand washing behavior would have a ripple effect for future generations. Hand washing with soap is part of the concept of hygiene, which forms part of the social studies syllabus in primary schools. Children spend most of their active hours in a school environment and may also have different motivators and barriers to hand washing.

Hand washing with soap particularly at critical moments includes after using the toilet and before handling food is a key cost effective and life saving intervention. Research in several developing countries illustrates that lack of soap is usually not the barrier with the vast majority of even the poor households having soap at home rather the problem is that soap is rarely used for hand washing. This research is aimed at coming up with new knowledge concerning factors which will promote hand washing with soap. It will also assist in planning and delivering of health services to target groups.

From the research findings, the results have shown that the challenges facing uptake of hand washing with soap programme in schools include lack of provision of soap, disappearance of soap and hand washing facilities, inadequate water supply and low commitment by the entire school administration. If these challenges will not be addressed, then school days will continuously be lost by the school children due to diarrheal diseases hence poor school performance and unhealthy school children and the entire community. 


\subsection{Recommendations}

Based on the above findings, summary and conclusion, some recommendations for improving uptake of hand washing with soap programme in schools in Tana Delta Sub County include provision of soap by the school administration for hand washing. Effective hand washing can only achieve its desired objective by use of soap. This is because pathogenic organisms attached to hands can only be detached by use of soap; the following recommendations were thus made:

1. The school administration should also provide adequate water supply for hand washing in schools. This can upscale and sustain hand washing with soap programme. Effective cleaning of hands can only be practiced in schools if there is adequate water supply. Without water in schools, this programme cannot be effected and hence we will have unhealthy school children. The school administration should make an effort of lobbying from partners to get support in terms improving water adequacy.

2. The schools which had not started hand washing with soap programme to be encouraged to do so in order to upscale the programme and improve awareness activities to the school children for the purposes of reducing diarrheal diseases among school going children. School children spend most time at school and whatever information they get from school will stick into their minds and easily passed to their parents back at home. This will improve awareness in the entire school.

3. Formation of school health clubs to be emphasized which will in cooperate hand washing with soap programmes. These clubs can start programmes like choirs, poems and concerts with messages on the importance of hand washing with soap. Demonstration and installation of hand washing facilities at strategic places like outside the toilets and at the kitchen are very important sites. These are visible sites and will actually remind a student to wash hands all the time after using hands at critical moment.

4. Regular capacity building and follow up of teachers to ensure that the programme is implemented will assist in improving uptake of hand washing with soap programme in schools. Follow up will act as a monitoring system and for success of any programme, there has to be a regular checkup. This will assist in getting to know the progress of the programme and if there are any corrections to be made, then they can be captured early and intervened before the situation becomes worse.

\section{Acknowledgement}

First, I thank the Almighty God for enabling me carry out the study. I would like register my appreciation for the significant contribution made by all those who, in one way or another assisted me during the process of preparing this research project .I give special thanks to the Government of Kenya through the Ministry of health for allowing me take this course at Jomo Kenyatta University. Special thanks go to Madam Evaline Datche who has been my lecturer on research methods as well as my supervisor in research project for her guidance and advice. I also give special thanks to Madam Fridah Theuri, the deputy director of JKUAT who has also been encouraging on completion of research proposal on time. Special thanks also go to the Director of JKUAT for his concern on matters pertaining to seriousness on research project. I would also like to thank all my fellow students who joined efforts in correcting the flow of my research project

\section{References}

[1]. Ajzon, L., \&Fishbein, M. (1980).Understanding the Attitudes and predicting social behavior Englewood cliffs, NJ prentice.

[2]. Best, M., Nevhavset, D., \&Semmelweis, I. (2004). The birth of infection control. Qualsaf Health care pmc free article (pubmed) 13,233-234.

[3]. Bolt, M., Shordt, K., \&Krukkert,L. (2006).School sanitation and Hygiene Education Netherlands: International water and sanitation centre.

[4]. Boyce, J.M., \&Pittet, D.(2002). Health care infection control practices Advisory committee, HICPA/SHEA/APIC/IDSA.

[5]. Curtis, V.A., Garbrah- Aidoo, N., \& Scott, B. (2007).Ethics in Public HealthResearch.AMJ public health (pmc free article), 97,634641.

[6]. Fishbein, M.,\&Guinan, M. (1996).Behavioral science and Public Health. Public Health Rep. (pmc free article) (pubmed) $111,5-10$.

[7]. Glanz, K., \&Rimet, B., K., \& Lewis, F., M. (2002).Health Behaviour and Health Education Theory.San Fransisco.

[8]. Itvetly, S., R., Morris, S., S., \&Pisani, V. (1997).Prevention of diarrhea in young children in developing counties.Busi World Health Organ (Pmc freearticle)(pubmed), 75,163-174.

[9]. Jarvis, W., R. (1994) .The semmelweis Lesson Forgotten? Lancet, 344, 1311-1312.

[10]. Kretzer, E., K., \&Latson, E., L. (1998) .Behavioral interventions to improve infection Control practices. Am J infect control, (Pubmed), 26, 245-253?

[11]. Mandell,G., L.,Bennet, J., E.,\&Dollin, R. (2000). Principles and practices of infectious diseases. Philadephia P.A: Churchill Livingstone.

[12]. McElroy, K., R., Bibeau, D., \&Stecker, A., et al. (1988).An ecological perspective on health promotion.Pubmed 15, $351-377$.

[13]. Monto, A., S. (2002). Epidemology of viral respiratory infection AM J med 112 (SVPPI 6A), (pubmed) 45-125.

[14]. Sallis, J., F., \& Owen, N. (2002). Ecological models of Health Behaviors.

[15]. Glanz, K., \&Rimet, B., K., \& Lewis, F., M. (2002).Health Behaviors and Health Education Theory, Research and Practice $\left(3^{\text {rd }}\right.$ Ed.)San Fransisco.

[16]. Scott, B., Curtis, V., \&Rabie, T. (2003). Protecting children from diarrhea and acute respiratory infections: the role of hand washing promotion in water and sanitation programmesWHO Reg Health Forum 7, 42-47.

[17]. Sproat, L., J., \&Inglis, T., J., J. (1994).A multicentre survey of hand hygiene practice.(pubmed) 26, $137-148$. 
[18]. Tulchinsky, T., H.,\&Varavikova, E (2000).The new Public Health. San diego.Academic press.

[19]. Yaicin, S., S., Yaicin, S.,\&Aitin, S (2004) .Hand washing and adolescents.(pubmed) 16, 371 - 376.

\section{APPENDICES \\ APPENDIX 1 \\ LETTER OF INTRODUCTION} RE: CHALLENGES FACING UPTAKE OF HAND WASHING WITH SOAP PROGRAMME IN SCHOOLS IN TANA DELTA DISTRICT.

I am a student at the Jomo Kenyatta University of Agriculture and Technology Mombasa (CBD) campus carrying out a research on challenges facing uptake of hand washing with soap programme in schools in Tana Delta Sub County.

This information will be used by the researcher in an ethical manner and you are assured of confidentiality obtained. All the information is for research purpose only and nothing else.

This is therefore to humbly request for your cooperation.

Thank you

Davies K. Mwachiro

\section{APPENDIX 2}

QUESTIONAIRE

A QUESTIONAIRE ON CHALLENGES FACING UPTAKE OF HAND WASHING WITH SOAP PROGRAMME IN SCHOOLS IN TANA DELTA SUB COUNTY

INSTRUCTIONS: KINDLY TICK WHERE APPROPRIATE

Demographic information

Name of the school.

Division.

Sub County

School enrolment.

Date school visited

\section{SECTION A}

1. What do you understand by hand washing with soap?

a) Making hands clean

b) Cleaning hands with water

c) Wiping hands with linen

d) Cleaning hands with soap and water

2. Why is it important to use soap when washing hands?

a) It makes hands attractive

b) It makes hands clean

c) It removes dirt and germs/microorganisms which could cause diarrhea diseases

3. What is the children perception of dirt?

a) Something that can cause diseases.

b) Not aware

4. Which diseases are we likely to get if we do not wash our hands with soap?

a) Measles

b) TB

c) Diarrheal dieses

\section{SECTION B}

5. In which critical moments are we supposed to wash hands with soap?

a) After studying, after working, after brushing teeth

b) After cutting vegetables

c) After visiting the toilets, washing baby bottoms, before eating, handling 
d) Soiled baby linen, handling contaminated surface.

6. What are the school children risky hygienic practices?
a) Eating without washing hands, not washing hands after visiting the toilet, sucking of fingers,
b) Fetching water
c) Cleaning the toilet

7. What could be the reason for the above response?

a) Negligence

b) Lack of information

c) Shortage of water and soap

8. What kind of water source do you have in your school?
a) Borehole
b) Tap water
c) Roof catchment
d) Well
e) Others( specify)

9. Is the water source enough for school hygiene practices?

a) $\mathrm{No}$

b) Yes

10. Does your school provide soap for hand washing?
a) Yes,
(b). No

\section{SECTION C}

11. Did your school start a hand washing with soap programme?

a) Yes

b) No

c) Not applicable

12. When did you start a hand washing programme in your school?
a) 2 years ago
b) 1 year ago
c) 3 years ago
d) Not applicable

13. What are the motivational factors to hand washing with soap in your school?
a) Disgust, comfort, fun, fitting in, nurture.
b) Smell good, to be smart,
c) Enjoyable.
d) Not applicable

\section{SECTION D}

14. Are school children aware of the importance of hand washing with soap?
a) yes
b) $\quad \mathrm{No}$
c) Not applicable

15. What is the progress of the programme in your school?
a) Doing well
b) Not doing well
c) Not applicable

16. What are the challenges of the programme?
a) No enough water
b) Soap disappearance
c) Disappearance of hand washing facilities.
d) Not applicable
e) No provision of soap.

17. Is the head teacher and the entire staff supporting the programme?
a) No, because
b) Yes
c) Not applicable 